in excessive amounts to extract gold from crushed ore in ASGM. Through pollution of the air, water and nutrients, the mercury causes adverse health effects in miners and their families. However, ASGM can be performed without the use of mercury. This has been practiced for many years in a region in the Philippines with the gravity-borax method (GBM). With this method, the gold-containing ore concentrate is produced using a launder and a washing pan. As the last step, borax salt is added and the mixture blow-torched. The exposure to borax dust or fumes is limited and is not suspected of posing a health risk to the miner or the environment. The result is cleaner gold and no mercury spill. In order to spread the use of the GBM method, two intervention projects have been conducted in the Philippines. In combination with a civil society strategy, miners from the region using GMB have educated miners from other areas in the use of the GBM method. The success rate varied from area to area. In areas with a miners' organisation and back-up from the civil society, the miners were encouraged to shift method and the change was sustained. The intervention program is now introduced in Uganda and Mozambique with the help from miners using the GBM method. In Uganda, the activities are focused on the spread of information about the mercury-free method locally and regionally. In Mozambique, the core of the project is to determine the extent of ASGM and to introduce the GBM method.

\section{7e WHEN MINING SURROUNDS THE COMMUNITY: WORK, WELL-BEING, AND ENVIRONMENTAL MONITORING IN SMALL SCALE MINING IN THE PHILIPPINES}

JL Lu. National Institutes of Health, University of the Philippines Manila (UPM), Manila Philippines

\subsection{6/oemed-2018-ICOHabstracts.693}

This research on small scale gold mining (SSGM) in Benguet, Philippines draws from three different but complementary data sources in order to analyse work, well-being and environmental pollution in SSGM. The data sources were- 1. workplace inspection to assess working conditions, hazards, and work practices of miners coupled with interviews and focusgroup discussions; 2 . health assessment and laboratory examinations among indigenous miners; and 3. environmental monitoring of mercury in water samples across all 13 municipalities of Benguet. The work analysis showed accident risks from use of explosives, poor visibility in tunnels, exposure to dust during tunnelling, and chemical exposures to mercury and cyanide without protective equipment and proper ventilation. The workplace inspection of the underground tunnels showed safety infarctions including unsteady trenches, insufficient slopes, possibility of collapse of trenches, and the risk of subsidence. The sub-sample population of 89 SSGM reported prevalent health problems- hypertension (62\%), hypertensive cardiovascular disease (14\%), and dermatitis (4\%) Health injuries were secondary to blasting and stone crushing. Another data from a sub-population of 34 miners showed major causes for hospitalisation were trauma, ulcers, kidney and cardiac diseases. Low back pain was common and associated with heavy lifting $(p=0.001)$. Reticulocyte count was associated with total lifetime mining hours $(p=0.033)$. The mental status examination showed most deficits in repeat phrase and recent memory. For the environmental monitoring of mercury in 90 surface water and 40 drinking water samples, a considerable percentage exceeded the maximum contaminant level (MCL) of both the Philippine guideline $(0.001 \mathrm{mg} / \mathrm{L}$ for drinking sources, $0.002 \mathrm{mg} / \mathrm{L}$ for surface waters), and EPA $(0.002 \mathrm{mg} / \mathrm{L})$, above which levels can cause risk to health. All the three different but complementary data sources show the need for an occupational and environmental agenda addressing the health-safety aspects and technical-social issues in mining.

\section{$1637 f$ LEGISLATION AND BEST PRACTICES IN SMALL-SCALE MINING IN THE PHILIPPINES}

SF Lu. College of Arts and Sciences, University of the Philippines Manila, Philippines

\subsection{6/oemed-2018-ICOHabstracts.694}

This study analyses the small-scale mining activities and the best practices for mercury-free gold mining. The data were based on literature, national laws and modules for small-scale mining, as well as interviews of major stakeholders in small scale mining in the Philippines. Currently, there are two national legislations on small-scale mining and an executive order to compliment these national laws, Presidential Decree 1899, which allowed for small-scale mining in the Philippines, and Republic Act 7076, which introduced guidelines for local miners on artisanal mining. Executive Order 79 prohibits the use of mercury in small-scale mining, however it goes against other legislative acts in place regulating the use of mercury for industrialization. Furthermore, the Order states that smallscale mining is not allowed outside the 'Minahang Bayan (People'sMining)', which was established to regulate small-scale mining. This is inconsistent with President Decree 1899 which allows for mining activities. There are thousands of illegal small-scale mining, as they cannot adhere to the administrative requirements set by the local government units. Hence, there is a need to revise and amend the existing laws to serve and benefit the local Filipino miners. Among the best practices in the approach to mercury-free mining in the Philippines showed the need for a participatory approach among major stakeholders such as the small scale miners, local government, and civil society-advocacy groups, the need for technical knowledge of shifting to mercury-free mining, respect for culture of the indigenous miners, and capacitating strategies to maintain the mercury-free technology in mining. There are also corollary programs aimed to promote mining revenue, compliance among miners for increased awareness, and to decrease hazards and conflicts. Hence, there is a need for the following- a ground-to-top reformulation of the law to cater to the needs of the miners and a harmonisation of national laws with international guidelines.

\section{MINING OCCUPATIONAL SAFETY AND HEALTH: HAZARDS AND GOOD PRACTICES IN FORMAL AND INFORMAL MINING}

${ }^{1}$ Erik Jørs*, ${ }^{2}$ Jane Froelund Thomsen. 'Department of Occupational and Environmental Medicine, Odense University Hospital, Odense, Denmark; ${ }^{2}$ Department of Occupational and Environmental Medicine, Bispebjerg University Hospital, Copenhagen, Denmark

10.1136/oemed-2018-ICOHabstracts.695 
Aim of special session A presentation of hazards and health problems in mining and the possibilities for prevention with improved Occupational Safety and Health in small- and largescale mining worldwide.

Presenters: ${ }^{1}$ Erik Jørs, ${ }^{2}$ Muchtaruddin Mansyur, ${ }^{3}$ Liem J Fuk, ${ }^{4}$ Stephane Hallé, ${ }^{5}$ Cas J Badenhorst, ${ }^{6}$ Helmut Ehnes

${ }^{1}$ Department of Occupational and Environmental Medicine, Odense University Hospital, Odense, Denmark.

${ }^{2}$ Universitas Indonesia - Faculty of Medicine, Department of Community Medicine, Jakarta, Indonesia

${ }^{3}$ Prodia Occupational Health Institute International, Jakarta, Indonesia

${ }^{4}$ Ecole de technologie supérieure, Montreal, Canada

${ }^{5}$ Anglo American plc., Johannesburg, South Africa

${ }^{6}$ International Section of the ISSA Mining on Prevention in the Mining Industry, Bochum, Germany

\section{6a INTRODUCTION TO MINING HAZARDS AND GOOD PRACTICES IN FORMAL AND INFORMAL MINING}

E Jørs. Department of Occupational and Environmental Medicine, Odense University Hospital, Odense, Denmark

\subsection{6/oemed-2018-ICOHabstracts.696}

Mining is among the most hazardous workplaces at a global level. Accidents as well as pneumoconiosis, poisonings and cancers take a high dead toll among miners. Other diseases due to heavy workload, noise, vibrations and high or low temperature such as hearing loss, white fingers, carpal tunnel syndrome and muscle and back pain are not deadly but still serious for the miners. In this session we will be presented for miner's liver and kidney diseases, which might have a connexion to the high temperatures, dehydration and salt depletion in mines as also described in some farmers studies from Central America. Implementation of OHS preventive measures in mining is often difficult due to the mostly unregulated small scale and artisanal mining taking place in mainly low-income countries were rules and regulations are hard to enforce. Some key issues in prevention is appropriate laws and their enforcement, banning of toxic mining processes, better environmental control and education and new technology such as cooling wests used for prevention of heat distress among others.

\section{6b MINING WORKERS, ADMINISTRATIVE TASK, OBESITY, HYPERTRIGLYCERIDEMIA, AND YOUNG WORKERS INCREASED RISK LIVER FUNCTION ELEVATION AMONG INDONESIAN MALE WORKERS}

\footnotetext{
${ }^{1} \mathrm{M}$ Mansyur*, ${ }^{2} \mathrm{JF}$ Liem. 'Universitas Indonesia - Faculty of Medicine, Department of Community Medicine, Jakarta, Indonesia; ${ }^{2}$ Prodia Occupational Health Institute International, Jakarta, Indonesia
}

\subsection{6/oemed-2018-ICOHabstracts.697}

Introduction Mining workers have potential risks to be exposed by many toxicants. Due to the majority of toxicants metabolised through the liver this may be high risk of the liver function alteration due to occupational and non-occupational health hazards exposures. The purpose of this study was to explore the risk of mining worker to have liver function elevation (LFE) adjusted by other risk factors.

Methods A comparative cross sectional study was conducted to examine the secondary data of 2016 annual medical examination results of 5634 workers from six various industries in Indonesia. The data subjects consisted of 447 of those who had a LFE compared with 1341 subjects were randomly chosen from those data whose were normal in liver function enzyme. Liver function elevations were considered on the basis of serum aspartate aminotransferase and/or alanine aminotransferase level more than 5 points above reference levels. The risk of mining workers to have liver function elevation were calculated using Odds Ratios and adjusted by Type of Task, Chemical Exposure History, Age, Body Mass Index, Medical History and Triglyceride Level.

Result This study analysed 1781 male workers (31.0 \pm 7.4 year). No significant associations were observed between outcome and medical history of diabetes mellitus and liver disease as well as alcohol consumption, smoking, physical exercise, and chemical exposure history. Risk factors associated with LFE were identified including obesity (OR 4.0, 95\% CI: 3.1 to 5.0 ), work in mining sector (OR 2.0, 95\% CI: 1.6 to 2.6), role as administrative worker (OR 1.4, 95\% CI: 1.0 to 1.8 ), age $<35$ years (OR 1.4, 95\% CI: 1.1 to 1.9 ), and hypertriglyceridemia (OR 1.6, 95\% CI: 1.3 to 2.1 ) respectively.

Discussion Attributed risk factors of LFE among worker were identified including occupational, individual and modifiable metabolic risk. Further research is needed to explain the role of occupational exposures in LFE among miners.

\section{6c MINING WORKERS, OBESITY, KIDNEY DISEASE HISTORY, AND HYPERTENSION INCREASED RISK IMPAIRED KIDNEY FUNCTION AMONG INDONESIAN WORKERS}

${ }^{1} \mathrm{JF}$ Liem*, ${ }^{2} \mathrm{M}$ Mansyur. ${ }^{1}$ Prodia Occupational Health Institute International, Jakarta, Indonesia; '2Universitas Indonesia - Faculty of Medicine, Department of Community Medicine, Jakarta, Indonesia

\subsection{6/oemed-2018-ICOHabstracts.698}

Introduction Kidney Disease is a major health problem among productive age group. The purpose of this study was to explore the risk of mining worker to have Impaired Kidney Function.

Methods A comparative cross sectional study was conducted to examine the secondary data of 2016 annual medical examination results of 5634 workers from six various industries in Indonesia. The data subjects consisted of 90 of them who were considered Impaired Kidney Function (IKF) compared with 450 data subjects were randomly chosen from those who were normal serum creatinine. Those who have serum creatinine (SCr) level $>1.2 \mathrm{mg} / \mathrm{dL}$ and $>0.9 \mathrm{mg} / \mathrm{dL}$ for male and female respectively were categorised as IKF. Logistic regression analysis was used and the risk of mining workers to have IKF were calculated using Odds Ratios and adjusted by individual risk factors (age, hypertension, obesity, history of diabetes, history of kidney disease) as well as with occupational risk factors (type of task, chemical exposure, and heat exposure).

Result This study analysed 540 workers (32.4 years +8.5$)$. No significant associations were observed between outcome and medical history of diabetes mellitus, alcohol consumption, smoking, physical exercise, as well as chemical exposure history. Risk factors associated with IKF were identified including work in mining sector (OR 6.4, 95\% CI: 4.0 to 10.3), obesity (OR 2.5, 95\% CI: 1.5 to 4.0), grade II hypertension (OR 3.8, 95\% CI: 1.1 to 13.2), history of kidney disease (OR 9.7, 